\title{
Photovoltaic Systems and Net Metering in Greece
}

\author{
Fotis Mavromatakis \\ Department of Electrical Engineering \\ Technological Educational Institute of Crete \\ Heraklion, Crete, Greece \\ fotis@staff.teicrete.gr
}

Hara Haritaki

Department of Accounting and Finance

Technological Educational Institute of Crete Heraklion, Crete, Greece

haritaki@staff.teicrete.gr

\author{
George Viskadouros \\ Department of Electrical Engineering \\ Technological Educational Institute of Crete \\ Heraklion, Crete, Greece \\ viskadouros@staff.teicrete.gr \\ George Xanthos \\ Department of Business Administration \\ Technological Educational Institute of Crete \\ Heraklion, Crete, Greece \\ xanthos@staff.teicrete.gr
}

\begin{abstract}
The latest measure for the development of photovoltaics in Greece utilizes the net-metering scheme. Under this scheme the energy produced by a PV system may be either consumed by the local loads or be injected to the grid. The final cost reported in an electricity bill depends upon the energy produced by the PV system, the energy absorbed from the grid and the energy injected to the grid. Consequently, the actual electricity consumption profile is important to estimate the benefit from the use of this renewable energy source. The state latest statistics in Greece for households reveal that the typical electrical consumption is $3750 \mathrm{kWh}$ while $10244 \mathrm{kWh}$ are consumed in the form of thermal energy. We adopt in our calculations the above amount of electrical energy but assume four different scenarios. These different hourly profiles are examined to study the effects of synchronization upon the final cost of energy. The above scenarios are applied to areas in different climate zones in Greece (Heraklion, Athens and Thessaloniki) to examine the dependence of the hourly profiles and the solar potential upon the financial data with respect to internal rate of return, payback times, net present value and the levelized cost of energy. These parameters are affected by the initial system cost and the financial parameters.
\end{abstract}

\section{Keywords-photovoltaic; net metering; modeling; financial}

\section{INTRODUCTION}

One of the support mechanisms to promote photovoltaic (PV) technology and reduce the energy costs for residential and commercial customers is related to the local production of renewable energy (self-production). The net metering scheme involves grid connected systems and is available in many countries worldwide. Utilities can better manage peak loads since PV systems generate most of their power around noon time. Local power production allows reducing the strain in the electrical distribution system and the transmission and distribution losses. Part of the energy generated by the PV system may be consumed by the loads (self-consumption) of the owner of the PV system, e.g. lights, refrigerators, pumps, etc, while any surplus energy will be exported to the grid. The owner of the PV system will be billed for the net energy which is basically equal to the energy retrieved from the grid minus the energy injected to the grid. In Greece the relevant law was introduced in 2014. Recently, in 2017, the Greek state setup the details of net metering and introduced the concept of virtual net metering. Under this scheme the points of energy production and consumption may well differ electrically or spatially. In addition, it is foreseen that a customer may incorporate more points of consumption into the energy balance agreement.

In this work we focus on the net metering scheme for residential customers. The total billing of energy in households involves basically two parts. The first part refers to the cost of the actual energy consumed by the customer ("energy supply charges"). The second part refers to a few regulated costs like those related to transmission, distribution, services of common wealth, reduction of gas pollution, special fees and other charges ("regulated costs"). The "energy supply charges" depend upon the specific energy supplier company, which may be other than the Greek Public Power Corporation (PPC), whereas the "regulated costs" are common to all energy suppliers. Both categories of costs are calculated in a specific way and in this work those defined by the PPC are adopted. We explore the implications of net metering at three different geographical areas in Greece. For each area, we assume a number of hourly profiles for the loads resulting to the same annual energy consumption. Adopting typical values for the financial data the payback times, net present value and the levelized cost of energy are calculated and compared.

\section{MODEL DATA}

The input model data may be distinguished to two categories. The first involves the data related to the photovoltaic system while the second involves the data related to the consumer load. The PV*SOL software was utilized for the hourly PV calculations [1]. This software makes use of the METEONORM database to retrieve solar irradiance and meteorological data for the selected sites: Heraklion - Crete, 
Athens - Attica and Thessaloniki - Northern Greece [2]. The peak power of each PV system was chosen to fully match the consumed energy. In all cases, the PV system comprises of a typical commercial inverter with a nominal power around 2.5 $\mathrm{kW}$ while the modules are characterized by peak power in the range of $250-300 \mathrm{~W}$ at STC conditions. Table I below summarizes the basic data for all three sites.

TABLE I. BASIC DATA

\begin{tabular}{|c|c|c|c|}
\hline Site & GHI & Gt & Pp \\
\hline & $\left(\mathrm{kWh} / \mathrm{m}^{2}\right)$ & $\left(\mathrm{kWh} / \mathrm{m}^{2}\right)$ & $(\mathrm{kW})$ \\
\hline Heraklion & 1870 & 1960 & 2.43 \\
\hline Athens & 1710 & 1800 & 2.65 \\
\hline Thessaloniki & 1580 & 1670 & 2.80 \\
\hline
\end{tabular}

According to the Greek Statistical Authority in 2013 the average annual electrical energy consumption of a household is $3750 \mathrm{kWh}$, while the corresponding total energy requirement amounts to $13994 \mathrm{kWh}$ [3]. The additional energy of 10244 $\mathrm{kWh}$ refers to thermal energy which is used for space heating $(84.9 \%)$, water heating (4.4\%) and cooking $(9.7 \%)$. The fuel mostly used to generate thermal energy is diesel oil $(60.3 \%)$, followed by wood burning (23.8\%). Other sources of energy follow with much smaller percentages. In this work we focus on the electrical energy and it is the energy of $3750 \mathrm{kWh}$ that will be considered in the net metering scheme. Since the "regulated costs" depend mainly upon the energy consumed from the grid, it is important to understand the concept of synchronization between the generation of PV power and the loads.

\section{A. The hourly energy profiles}

Formally, the degree of synchronization, $\mathrm{S}$, is defined as the ratio of self-consumed energy over the energy produced by the $\mathrm{PV}$ system. The self-consumed energy is calculated as the difference between the AC energy $\left(E_{a c}\right)$ produced by the PV system minus the AC energy injected to the grid $\left(E_{i n j}\right)$.

$$
S=\frac{E_{a c}-E_{i n j}}{E_{a c}}
$$

Formally, the degree of synchronization may vary from $0 \%$ to $100 \%$. The minimum degree refers to loads that are basically completely out of phase with the solar energy (e.g. only night loads) while the maximum refers to loads that exactly match the produced PV energy. Consequently, the billing costs depend upon the degree of synchronization since it affects the amount of energy consumed from the grid. The first load curve that is adopted assumes that all loads are on during the night resulting in the worst-case scenario (S1), i.e. highest cost for the consumer under the net metering scheme. The second scenario (S2) utilizes results from a short survey performed by the Centre of Renewable Energy Sources (CRES) in the area of Athens and the average hourly profile of all measurements is adopted in the current work [4]. The third load profile (S3) is available as a built-in profile in the software and is also adopted in this study. The specific profile refers to the energy consumption in a block of flats. Finally, the last scenario (S4) adopts a load curve centered close to noon time with a flat profile to increase the degree of synchronization. This may not be a real profile, but it is implemented to study the effects of increased synchronization. All profiles are shown Figure 1 in arbitrary units. The software normalizes these profiles, so that the total annual energy consumed by the household loads is $3,750 \mathrm{kWh}$.

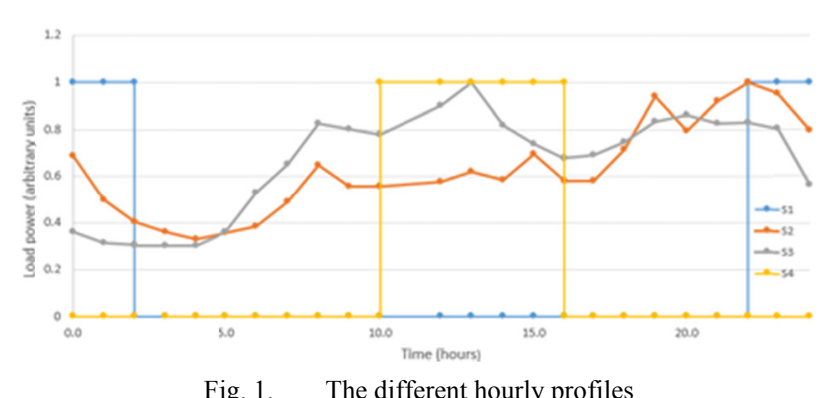

\section{B. Financial data}

As already mentioned, this work focuses on residential customers and in this case, the typical cost of energy is calculated with data provided by the PPC [5]. The energy bills are issued every four months, i.e. there are three clearance bills in one calendar year. According to the residential tariff as stated by the PPC, the cost of a typical four-month summer period in Heraklion, without net metering, amounts to 220 euros. This value does not include charges that are collected by the PPC and are, then, attributed to the local municipality according to the Greek law. In the worst-case scenario of net metering (S1), where all loads are active during the night, the corresponding cost drops to around 92 euros. Contrary to scenario S1, the best scenario is S4 where the loads are active around noon time. The total cost rises to 28 euros under this scenario, concerning the same four-month summer period. This scenario (S4) is an ideal scenario and is shown for comparison purposes. It is unlikely to consider a residence with such a profile. During summer time the PV energy is usually higher than the energy required by the loads but still there is a nonzero contribution to the total cost. This is because even in the case of zero net energy, there is a minimum cost set by the PPC. For every site and every scenario, the four-month billing costs are calculated to determine the annual electricity and savings costs under the net metering scheme. These costs are adopted in the financial calculations concerning the viability of the investment. Another interesting parameter is the annual degree of synchronization which is shown in Table II for all three sites and scenarios. The dependence of the savings upon the degree of synchronization is evident. Similar costs are calculated for the other two cities and are not repeated here. The total annual cost of energy without net metering rises to 664 euros for a residence. It is clear that even in the worst-case scenario it is still worth considering net metering to reduce the cost of energy.

TABLE II. DEGREE OF SYNCHRONIZATION

\begin{tabular}{|c|c|c|c|c|}
\hline & S1 & S2 & S3 & S4 \\
\hline Heraklion & $0.0 \%$ & $37.8 \%$ & $44.5 \%$ & $71.3 \%$ \\
\hline Athens & $0.0 \%$ & $37.3 \%$ & $43.4 \%$ & $70.1 \%$ \\
\hline Thessaloniki & $0.0 \%$ & $36.7 \%$ & $42.4 \%$ & $68.2 \%$ \\
\hline Cost of energy & \multicolumn{5}{|l}{} \\
\hline Heraklion (1 yr) & $285 €$ & $204 €$ & $200 €$ & $132 €$ \\
\hline
\end{tabular}




\section{DISCUSSION}

The use of net metering by residential customers in three different areas and climate zones in Greece is considered in this work. The cost of energy for each scenario is practically the same for all sites explored, while the annual degree of synchronization shows minor variations (Table II). The financial metrics used to evaluate the viability of the investment of such domestic PV systems involve the levelized cost of electricity (LCOE), the simple payback time (PBT), the net present value (NPV) and the internal rate of return (IRR). These are calculated following the formulation provided by the National Renewable Energy Laboratory (NREL) [6]. The LCOE represents the cost of energy per $\mathrm{kWh}$ produced by the PV system over the investment horizon, while the simple PBT represents the time it takes for the net revenues to equal the initial investment cost. The NPV represents the savings over the same period taking in terms of the current value of the money. The IRR represents the deflated cost of capital at which the NPV becomes zero during the life time of the project. The basic financial parameters used in the calculations are summarized in Table III. In this work the investment time interval is set to 25 years and basically, reflects the duration of the contract signed with the Hellenic Electricity Distribution Network Operator S.A. under the net metering scheme. However, it must be made clear that this doesn't represent the actual life time of a PV module. It formally represents the time interval, at the end of which, a module may not produce less than $80 \%$ of its initial power rating (guaranteed by the manufacturers). A module will keep producing energy although degraded by about $0.4 \% / y r[7,8]$.

TABLE III. FINANCIAL DATA

\begin{tabular}{|c|c|c|c|c|}
\hline $\begin{array}{l}\text { Initial } \\
\text { cost } \\
(€ / \mathrm{kW})^{1}\end{array}$ & $\begin{array}{c}\text { System } \\
\text { degradation }^{2}\end{array}$ & $\begin{array}{c}\text { Inverter } \\
\text { replacement } \\
(€ / \mathrm{kW})^{3}\end{array}$ & $\begin{array}{l}\text { WACCnom } \\
\text { \& Inflation }\end{array}$ & Scenarios \\
\hline $1,000.0$ & $0.4 \%$ & 350 & $7 \% \& 4 \%$ & $\begin{array}{l}\text { S1, S2, } \\
\text { S3, S4 }\end{array}$ \\
\hline $1,250.0$ & $0.4 \%$ & 350 & $7 \% \& 4 \%$ & $\begin{array}{l}\text { S1, S2, } \\
\text { S3, S4 }\end{array}$ \\
\hline $1,500.0$ & $0.4 \%$ & 350 & $7 \% \& 4 \%$ & $\begin{array}{l}\text { S1, S2, } \\
\text { S3, S4 }\end{array}$ \\
\hline \multicolumn{5}{|c|}{$\begin{array}{l}{ }^{1} \text { Initial cost of PV system } \\
{ }^{2} \text { System degradation per year } \\
{ }^{3} \text { Inverter replacement per ten years } \\
{ }^{4} \text { WACCnom: nominal weighted average cost of capital } \\
{ }^{5} \text { Inflation: the annual inflation rate }\end{array}$} \\
\hline
\end{tabular}

A replacement time of string inverters of 10 years, considering a good quality inverter, is adopted. In such small PV systems the owner of the system may carry out the operation and maintenance costs (O\&M) and thus, do not pay any costs for the cleaning of the modules and the inverter, the inspection of cable connections, etc. Finally, a fixed cost of 300 euros is incorporated in year 0 costs as a grid connection fee foreseen by the state law. A single-phase grid connection is assumed since the examined PV peak power is small. To examine the viability of the investment it is crucial to integrate local economy parameters such as the inflation and the nominal weighted average cost of capital (WACC). Inflation is an increase in the cost of goods and services per unit time. For convenience, inflation is customary to refer to a year. Based on the performance of economic indicators, an average annual inflation rate of $4 \%$ was selected [9]. On the other hand, WACC is associated with the amount of profit that obtained from saving capital. Net Metering is nothing more than an agreement with a power company, enabling the consumer to install a solar power system to meet part or all of the energy consumption. The power company compensates the energy generated by the solar modules with the power consumed by the owner of the photovoltaic system. When there is excess energy because the consumption is low it will be supplied to the grid. On the other hand, when the PV system does not produce enough energy (e.g. clouds or night time) then energy will be consumed from the grid. When the demand for electricity is consistent with production, the compensation price increases and thus, depreciation of capital spent for the installation of the system becomes faster. It should be noted that the excess energy does not lead to income growth due to lack of agreement in tariff for net metering systems.

The analysis of a household in Heraklion shows that, in the worst-case scenario S1 (just night loads), the breakeven point is 13 years for a PV system price of $1,250 € / \mathrm{kWp}$. This parameter ranges from 9 to 16 years considering system prices of 1,000 and $1,500 € / \mathrm{kWp}$ and all possible scenarios. The cash flow analysis for this household meets the agreement mentioned earlier for the electrical energy demand and shows that in the consumption profile S2 (mixed daily and nights loads) the breakeven point is 8 years for a PV system price of 1,250 $€ / \mathrm{kW}$. Generally, in the case of scenarios S2 and S3 which better represent everyday profiles, the breakeven points drop to 7, 8 and 12 years for the corresponding initial system costs reported in Table III. The financial savings for these consumption profiles in Heraklion are very close to 3,600 euros (NPV) while the internal rate of return is close to $11-12 \%$ for the price of $1,250 € / \mathrm{kW}$ which is quite satisfactory since the real average cost of capital in the calculations is $2.9 \%$. If the real cost of capital is below the IRR value of $11-12 \%$, then the investment is viable (Table IV). The analysis for the cities of Athens and Thessaloniki also confirms that the worst-case scenario is S1 while scenario S4 is the best one as expected. However, both are unlikely to occur under typical conditions. Scenarios 2 and 3 are more realistic and provide very similar results for all cities despite the different origins of the hourly profile data. The financial savings range from around $2,300 €$ $(1,500 € / \mathrm{kWp})$ to $3,700 €(1,000 € / \mathrm{kWp})$ which are, of course, lower than the corresponding values in Heraklion due to the increased cost of the PV system $(2.43 \mathrm{kWp}$ vs $2.80 \mathrm{kWp})$. It was necessary to increase the installed PV power since the solar irradiance in northern Greece is reduced by around $17 \%$ with respect to the solar irradiance in Heraklion, Crete while the household electrical loads remain the same among all cities. The internal rates of return for the typical scenarios S2 and S3 are around $12 \%$ for Heraklion, $10 \%$ for Athens and $9 \%$ for Thessaloniki adopting the unit cost of $1,250 € / \mathrm{kW}_{\mathrm{p}}$. Since the real cost of capital of $2.9 \%$ ( $7 \%$ nominal and $4 \%$ inflation) is less than these IRRs, the investment is viable with a net present value ranging from around 3,000 to $3,600 €$.

The breakeven times are nine (9) years for Heraklion and twelve (12) years for the other two cities for the same scenarios suggesting that a residential customer will benefit from the net 
metering scheme. Furthermore, depending on the size of the PV system the savings in $\mathrm{CO} 2$ emissions range from 53,000 to $62,000 \mathrm{~kg}$ [10]. Finally, the Levelized Cost of Energy (LCOE) is also calculated, although it is not directly related to the net metering measure. The high solar potential in Greece offers the opportunity to establish low LCOE values with respect to other European countries. Under the data given, it is calculated that the LCOE ranges from the minimum of $0.052 € / \mathrm{kWh}$ in Heraklion and for a system cost of $1,000 € / \mathrm{kWp}$ to a maximum of $0.081 € / \mathrm{kWh}$ in Thessaloniki and for a system cost of 1,500 $€ / \mathrm{kWp}$.

TABLE IV. ECONOMIC METRICS FOR A HOUSEHOLD IN HERAKLION

\begin{tabular}{|c|c|c|c|c|}
\hline Investment Area & \multicolumn{4}{|c|}{ Heraklion } \\
\hline Consumption profile & $\mathrm{S} 1$ & $\mathrm{~S} 2$ & $\mathrm{~S} 3$ & $\mathrm{~S} 4$ \\
\hline Synchronization $(\%)$ & $0.0 \%$ & $37.8 \%$ & $44.5 \%$ & $71.3 \%$ \\
\hline LCOE $(€)$ & \multicolumn{5}{|c|}{0.0613} \\
\hline Breakeven (year) & 13 & 9 & 9 & 8 \\
\hline IRR & $8.4 \%$ & $11.5 \%$ & $11.6 \%$ & $14.0 \%$ \\
\hline NPV $(€)$ & 2,164 & 3,593 & 3,625 & 4,776 \\
\hline Simple PayBack (year) & 8.8 & 7.3 & 7.2 & 6.3 \\
\hline $\mathrm{P}_{\mathrm{p}}=2.43 \mathrm{kWp}$, Cost $1,250 € / \mathrm{kW}_{\mathrm{p}}$ \\
\hline
\end{tabular}

These results agree with studies of the LCOE [11]. It is estimated that the final savings will increase since the formal clearance time interval for the energy consumed and produced is three years while the simulations are conducted on an annual timeline. Future work involves the simulation of solar data with 1-minute resolution to explore the effect upon the degree of synchronization since hourly data smooth out any shorter time variations. Furthermore, it is interesting to examine the case where the energy required to supply all kind of residential loads may be in the form of electrical energy excluding the use of wood, natural gas, LP gas or diesel oil for e.g. heating, cooking. Heat pumps with a high coefficient of performance can account for the heating loads (space heating, hot water).

\section{CONCLUSIONS}

In this paper we present the results from the economic analysis of PV systems under the net metering scheme in different cities and climate zones in Greece (Heraklion, Athens and Thessaloniki). Several input parameters like the initial system cost, inflation, cost of capital and other parameters are used to examine different scenarios for potential investors of small residential PV systems. Residential customers may adopt the net metering scheme to reduce the cost of energy bills. The lifetime earnings (NPV) for a residence in Heraklion amounts to around 3,600€ while the breakeven time occurs at the ninth $\left(9^{\text {th }}\right)$ year of operation for a system cost of $1,250 € / \mathrm{kW}_{\mathrm{p}}$. An IRR of $12 \%$ is calculated for the same site. The degree of synchronization is around $40 \%$ for typical household hourly profiles and it affects the final energy cost. Under the specific scenarios the breakeven point is 12 years, the IRR is around $9 \%$ and the NPV is a bit less than $3,000 €$ for a site in northern Greece.

\section{REFERENCES}

[1] Valentin Energy Software, PV*SOL Simulation Program for Photovoltaic Systems, Berlin, 2018

[2] METEONORM Global Meteorological Database for Engineers, Planners and Education, Version 4.0.95, Switzerland
[3] Greek Statistical Authority, Yearly Report, 2013, http://www.statistics.gr

[4] Center for Rewenable Energy Sources, http://www.cres.gr

[5] PPC, Residential Tariffs, https://www.dei.gr/en

[6] E. Drury, P. Denholm, R. Margolis, The impact of different economic performance metrics on the perceived value of solar photovoltaics, NREL Technical Report/TP-6A20-52197, 2011

[7] R. M. Smith, D. C. Jordan, S. R. Kurtz, Outdoor PV Module Degradation of Current-Voltage Parameters, NREL, World Renewable Energy Forum Denver, Colorado, May 13-17, 2012

[8] F. Vignola, J. Peterson, R. Kessler, F. Lin, B. Marion, A. Anderberg, F. Mavromatakis, PV module performance after 30 year without washing, 43rd Conference of the American Solar Energy Society (SOLAR 2014), San Francisco, California, July 06-10, 2014

[9] Interest Rates of Deposits and Loans, Bank of Greece, https://www.bankofgreece.gr/

[10] European CO2 Emission Data, https://www.eea.europa.eu/data-andmaps/indicators/overview-of-the-electricity-production-2/assessment

[11] C. Kost, S. Shammugam, V. Juelch, H. T. Nguyen, T. Schegl, Fraunhofer Institute for Solar Energy Systems ISE, Levelized Cost of Electricity, Renewable Energy Technologies, 2018 